\title{
As Instituições e o Mundo que Ajudaram a Construir
}

\author{
John M. McGwire \\ Da National Science Foundation e do Office \\ of Economic Opportunity (Consultant) \\ Tradução de Olga Ferrini de Faria
}

Fonte: Public Administration Review, Nov./Dez. 1971

Em passado recente nossas instituiçōes sociais, industriais e governamentais começaram a envolver-se ostensiva ou simbolicamente nos muitos problemas com que se defrontam as áreas urbanas. Interesses comerciais inseriram-se na questão dos habitantes dos guetos; universidades pululam em inúmeros centros urbanos; câmaras locais de comércio e a League of Women Voters colocaram-se na vanguarda do exército reformista; o departamento de agricultura encontrou para si uma missão urbana. A eventual deturpação de palavras ou atos que é parte de qualquer debate nacional de nenhum modo obscureceu o fato de que a conscientização das questões urbanas deu a todos os cidadãos responsáveis e interessados um campo para pensar e agir. DeuIhes, mental e emocionalmente, capacidade de segurar no cabo da caçarola que é o mundo.
Infelizmente, esse cabo terminou por ser mais importante, em si mesmo, do que a caçarola a que está ligado. Questões como política local de impostos, sistemas viários radiais e manutenção da ordem, perderam-se diante de tentativas de colocar a guerra, a subnutrição das populações rurais e o problema nacional dos tóxicos sob a rubrica de urbanos. Esses grandes problemas nacionais - lamentáveis e trágicos quanto possam ser - revestemse de caráter de importância para as áreas urbanas. Mas não devem ser tratados de maneira exclusiva por nossas instituições urbanas. A importância dos problemas de uma grande cidade vem sendo esvaziada por tentativas de colocar problemas nacionais sob a capa de urbanos.

Essa classificação agora funciona à maneira de um guarda-chuva: abrigando quase todo tipo de problema. A 
mesma dinâmica de sobrecarga de atribuições e de falta de atuação eficaz avança rapidamente.

Através do empirismo agressivo de muitos de nossos concidadãos nossas instituições estão sendo chamadas a fazer aquilo que não podem e, muitas vezes deixando de ser chamadas a fazer justamente aquilo que poderiam.

Tendo-se pronunciado freqüentemente sobre sua contribuçião para um briIhante futuro para todos nós, nossas instituições encontram-se agora em tal posição que qualquer declaração a respeito de um problema é tomada como promessa de solução total. As organizações aceitaram o princípio de que devem encarar o mundo com uma atitude mental positiva, quando as circunstâncias não justificam tal postulado.

Uma série de panacéias tem sido tentada para problemas insolúveis. Com efeito, nossas instituições fracassaram até o ponto de serem indecisas quanto a uma definição de si próprias, do que pretendem fazer e do que precisa realmente ser feito.

Com sua capacidade de organizar e aplicar recursos, nossas instituições sociais, industriais e governamentais estão de posse de um aparelhamento que possibilita o ataque a problemas sociais extensos e complexos. Mas se elas vão servir-nos de modo significativo e coerente, devemos saber o que cada uma delas pode e não pode fazer, e porque.

R. Scrv. Públ., Brasilia, 108 (1): jan/abr. 1973
LIMITAÇÕES

Por sua natureza, as instituições praticam três formas de autơlimitação. Em primeiro lugar isolam uma área específica de atuação. Esta área pode ser extensa ou não, seus elementos podem ser diversificados ou simples. O propósito pode ser afetar a área mediante a produção de conhecimentos, divulgação de informação, ou atuação direta. Em segundo lugar, as dimensões da área e, paralelamente, o propósito de atendê-la, requerem a escolha de um método organizacional que propicie a otimização do impacto dos recursos disponiveis. Esse método escolhido limita ainda mais a organização, porque requer uma equipe especializada. Em terceiro lugar, uma instituição necessita do apoio, dos serviços, da liderança e da cooperaçăo de outras para realizar sua missão. Ela age como membro de um grupo em que pode predizer o que sua congênere pode fazer, realmente fará, e como fará. Este entrosamento constante é 0 que integra as instituições num todo $e$ permite-Ihes operar.

Entretanto, no mundo atual, em que os problemas se apresentam coligados e interdependentes, a aplicaçăo maciça de recursos a prazo determinado em um dado objetivo torna-se um método questionável. Modernas noçōes sociais sobre "o que é importante" muram o caráter e a extensão das áreas de atuação. Uma vez que a mecânica interna de uma organização corresponde especificamente a determinado objetivo, há considerável dificuldade de ajustamento ao mundo exterior cambiante. Ademais, as louváveis conquan- 
to rigidas relações entre instituiçōes não podem ajustar-se facilmente a novas demandas.

$\mathrm{Na}$ década de 30 criou-se a Federal Housing Administration para promover a compra de casa própria pelos americanos, através do sistema de crédito. Considerando a situação financeira da época, a criação da FHA foi um marco na atuação do governo no campo da política habitacional. Seu objetivo era fornecer a possibilidade de casa própria; seu sistema, o da garantia de hipoteca através de seguro de crédito; seu quadro de pessoal, escolhido em razão da habilitação para desenvolver planos de risco; e seus elementos institucionais, as hipotecas, as empresas de construção e os empresários que decidiram valer-se da oportunidade implícita em tais garantias.

Ao definir seu objetivo a FHA teve de estabelecer que faixa da população atenderia, qual a natureza e extensão dos riscos que seguraria e onde suas garantias poderiam ter maior aproveitamento. Escolheu a faixa de americanos brancos que desejassem morar em áreas suburbanas como aquela a que poderia servir melhor, em maior número e com menor risco. Vinte e cinco anos depois a definição básica operacional da FHA não havia mudado. Nesse interim, a natureza e os direitos de cidadania haviam sido redefinidos, a estrutura demográfica do país alterada e a questão do que constituía moradia adequada passara a incluir novos fatores.
A FHA desenvolvera uma missão claramente definida e pagara pessoal para executá-la sob um esquema administrativo especifico. A rede de organizações que se formou para realizar esse objetivo nacional e, incidentalmente, seus subobjetivos particulares, apoiouse na previsibilidade de cada um de seus integrantes. Organizações especializadas, equipes técnicas e estruturas institucionais prenderam-se à definição original da missão. Em outras palavras, os fatores que tornaram a instituição eficaz numa situação estável limitaram sua capacidade de ajustamento a uma situação cambiante.

A tendência para a maximização do impacto não somente inibe a capacidade de manter sob observação os elementos em mudança, mas acaba por tornar-se um fim em si mesma. O deslocamento da atenção especial da área de atuação para a competiçãa interna é simples e atraente. O problema tornase mais claro porque os participantes são conhecidos e as questões limitadas. Melhor ainda, a organização pode manter seu "status" entre suas congêneres em razão do interesse comum na questão do desenvolvimento interno.

Externamente, a instituiçăo continua a atuar como se estivesse a serviço de seu objetivo, sem perceber que sua finalidade pode ter-lhe escapado. O resultado é que ela começa a desgastarse na preparação dos impactos. No processo, seus pronunciamentos e atos públicos tornam-se irrelevantes ou prejudiciais à sua imagem. Ela está mais interessada na sua promoção do que na eficácia de sua atuação na área de sua finalidade legal.

R. Serv. Públ., Brasilia, 108 (1): jan/abr. 1973 
Aqui, novamente, a FHA fornece exemplo interessante. Há alguns anos atrás, encontrei um funcionário do Departamento de Habitação e Desenvolvimento Urbano de St. Louis, Illinois. Durante nossa breve conversa, fiquei sabendo que ele pretendia reduzir a burocracia da organização, a fim de que o periodo de tempo entre a apresentação de um projeto de aplicação e a ação final pudesse ser diminuido de seis meses: de dois anos para um ano e meio. Mais tarde apurei que grande parte do tempo de processamento de uma aplicação era gasto numa série de providências internas que pouco tinham a ver com os objetivos da FHA, de propiciar a aquisição de casa própria no Pais.

Ademais, a tendência para a otimização pode ter sérias "conseqüências na contratação do pessoal e na opinião do pessoal sobre si mesmo. recrutamento e o treinamento visam à aquisição e ao desenvolvimento de todas as habilidades operacionais que a organização definiu como necessárias ao seu trabalho. A alta especialização torna-se a característica desejável para o empregado. Muitas vezes uma tal equipe de especialistas vem a sentir que possui qualificações suficientes em sua própria casa para identificar, estudar e resolver qualquer problema. Ao longo do tempo, essa valorização dos recursos internos toma - caráter de principio operacional e impede a aceitação de idéias ou informações vindas de fora. Evitando contribuições externas, a equipe começa a crer no que diz a si mesma, começa a julgar-se infalivel. Tanto individual como coletivamente, os membros da equipe vêem-se como um grupo de ho- mens honoráveis e sábios, sendo desafiados por um mundo bizarro e cático. Conseqüentemente, as relações formais e informais entre eles endurecem. O círculo vicioso que se estabelece - atitude da equipe/processamento/produto/atitude da equipe torna-se cada vez mais fechado. A supervalorização da eficiência interna, tanto intelectual como operacional passa a limitar a eficácia externa.

A noção de negociação passa a ser um método de operação, o que é desafiador. Tal situação não pode ser corrigida com a colaboração de consultores nem através de uma reorganização, pois o conceito que os empregados têm de si próprios é por demais enraizado.

\section{QUEBRANDO A RIGIDEZ}

O resultado de tudo isto é que nossas instituições estão atuando dispersivamente, ou paralisadas.

Examinamos algumas das maneiras pelas quais os objetivos são definidos e as organizações operam e, com esta base, podemos iniciar a exploração de algumas possibilidades de injetar flexibilidade nas equipes, na estrutura, e nos programas de nossas instituições.

Uma tentativa de quebrar a rigidez é mudar a utilização das equipes. Uma vez que as equipes permanentes tendem a enrijecer a operacionalidade interna das organizações, devem-se encoralar tentativas de - ou talvez mesmo determinar - mobilidade das equipes. Essas tentativas devem incluir toda -uma gama de novos procedimentos com o pessoal, tais como comissöes, seguros de saúde e de vida transferi- 
veis e recursos de hipotecas e aposentadorias que pudessem ser transferidos de um lugar ou empregador para outro. Investindo-se os beneficios e programas na pessoa ao invés de no empregador, as organizaçōes são forçadas a competir pelo trabalho e pelas idéias dos melhores disponiveis. Não mais controlarão o talento de cada um com seus sistemas estáticos.

Qualquer organização que opere à base de programas fixos ou captação de fundos encontra-se na necessidade de contratar equipes temporárias. Como justificar projetos é importante, essas organizaçőes agarram-se a quaisquer fontes de recursos que encontrem, para poder manter seus niveis de pessoal. Nesse processo, aplicam suas energias na automanutenção, ao invés de investi-las na missão para que foram criadas. Um banco nacional de técnicos altamente capacitados poderia absorver esse pessoal, beneficiando os indivíduos - através do alargamento de seus horizontes profissionais - e beneficiando igualmente, em última análise, as novas instituições a que esse pessoal serviria.

O banco não seria uma instituição passiva. Além de operar como centro de pessoal, ofereceria oportunidade de desenvolvimento profissional para que o indivíduo pudesse aprimorar e atualizar sua competência em ambiente que the faria conhecer e avaliar outras habilidades e procedimentos. Nesse aspecto, nossas universidades poderiam Servir como áreas de estágio entre os vários compromissos. Os benefícios Para os membros do banco e as esco- las seriam mútuos. Aqueles teriam acesso a uma série de disciplinas e estas poderiam aproveitar a experiência operacional corrente de um grupo de profissionais maduros.

Este sistema de usar universidades para embasar um processo contínuo de desenvolvimento de pessoal, dando à equipe maior flexibilidade pode parecer impraticável. Ele fornece, entretanto, as linhas gerais do tipo de rejuvenescimento de quadros que se poderá empreender. Em outras palavras, o de que necessitamos é criar sistemas, sejam eles acadêmicos ou não, que possam injetar nova capacidade de resposta, novas atitudes, nos modelos de comportamento daqueles que compõem as nossas instituições. Uma experiência pioneira nesse sentido é o Federal Executive Institute de Charlottesville, Virginia, que serve de centro de aperfeiçoamento de executivos do serviço público. O principal objetivo do instituto é alargar a visão do individuo e familiarizá-lo com idéias sobre a natureza e o curso das mudanças. Um beneficio adicional são as relaçōes pessoais que se estabelecem entre os participantes, que pertencem a vários campos de atividade do serviço público.

Há perigos significativos implicitos em tal atividade. $O$ empreendimento pode: a) ver-se presa do mesmo circulo vicioso que se propõe corrigir; b) ser absorvido no fortalecimento das inclinaçōes da organização a que serve. Um exemplo característico deste perigo é o uso de universidades como veículos de estreitamento técnico.

R. Serc. Públ., Brasília, 108 (1): jan/abr. 197.3 


\section{MUDANÇA DE IDÉIAS}

Não precisamos amarrar ainda mais nossas instituições entre si, precisamos lubrificá-las. Precisamos mudar nossas idéias de como nossas instituiçōes devem relacionar-se umas com as outras, na tentativa de obter vantagem de sua atuação articulada, ao tempo em que eliminaremos a rigidez hierárquica.

Por exemplo, cidades-modelo adotam um sistema de governo que circula de alto a baixo, do nacional ao local. O problema é que as cidades e os estados não mais aceitam a supremacia federal em muitas áreas especificas. Por outro lado, a participação na arrecadação representa um reconhecimento da incapacidade da hierarquia. Esta idéia oferece um desafio e uma recompensa aos governos que podem provar sua viabilidade através de sua capacidade gerencial e da criatividade com que podem conceber a executar programas sociais.

A história atual indica que nossas hierarquias estabelecidas estão em dificuldade e assim permanecerão até que se ajustem para fazer face aos problemas de hoje. O esforço passado não tem, necessariamente, validade corrente. "Que faz você para possuir prestígio?" É uma boa pergunta e será formulada constantemente. $O$ que significa que as instituições devem aprender a deslanchar-se: Devem abandonar o próprio interesse no seu "status" histórico e dedicar-se às suas tarefas, como integrantes de estruturas interorganizacionais temporárias, orientadas para a solução de problemas.

R. Serv. Públ., Brasilia, 108 (1): jan/abr. $197 \hat{\jmath}$
Devemos desenvolver uma política organizacional que reconheça a autonomia e singularidade de cada instituição em termos de seus objetivos $e$ capacidades, mas que meça o valor de cada uma pela sua eficácia. Tal visão premiaria a integração das organizações no ataque a um conjunto comum de problemas e na rápida rearticulação de suas relações quando novos problemas se apresentassem ou problemas conhecidos se alterassem. Elas seriam avaliadas pelo trabalho efetivamente realizado, e não pelo que se arrogassem. Seriam, com efeito, computadas por sua eficácia individual, sua flexibilidade e sua capacidade de articulação umas com as outras.

Devemos reconhecer que a unicidade de cada organização, deve-se à sua própria definição de objetivos e de métodos para alcançá-los. Pedir a uma organização que mude sua missão é pedir-Ihe demais. Pedir-lhe que amplie a visão que tem de seu objetivo e que contribua com suas atividades normais como puder é razoável. A General Motors objetiva o fabrico e a comercialização de veículos. Pedir-lhe que mudasse de objetivo seria tornar inútil sua forma de gerência $e$ ineficiente o seu quadro de pessoal. Ela deveria, entretanto, estar consciente de como suas atividades afetam as pessoas e os lugares onde opera. Deve reconhecer que pode estar contribuindo para a elevação dos custos sociais que um dia terá de pagar. Em outras palavras, deve ampliar a idéia que tem de si mesma e de seus objetivos para incluir os efeitos de seus atos. Deve identificar quais de seus processos po- 
dem ser utilizados ou alterados para diminuir esses custos eventuais.

As potencialidades especiais de cada uma de nossas organizaçōes devem ser utilizadas sempre que forem aplicáveis a uma questão de interesse social. 0 modo por que as organizações se associam umas às outras deve ser determinado pela possibilidade de seus atributos peculiares serem melhor aproveitados num esforço coordenado. Não devemos pedir-Ihes que mudem de finalidade, devemos inclui-las ou excluilas dos programas na medida em que suas finalidades e sua visão de si mesmas se ajustem ao que se necessita realizar. Nossas instituições, assim, não estarão prestigiadas nem desprestigia- das em razão de sua inclusão ou exclusão. Serão apenas usadas quando necessárias.

Nossas instituições devem ver-se como participantes de um sistema aberto, em que seu valor será dado por sua eficácia no papel que desempenham em relação a determinado problema.

As rivalidades egoistas que presidem as lutas por prestígio numa hierarquia sem conteúdo devem ser banidas.

Nossas instituiçōes devem ter a humildade de recuar diante daquilo que não podem empreender... e dizê-lo. 
